\title{
Teleology beyond explanation
}

\section{Sehrang Joo $^{1}$ | Sami R. Yousif ${ }^{1}$ | Joshua Knobe ${ }^{2}$}

\author{
${ }^{1}$ Department of Psychology, Yale University \\ ${ }^{2}$ Program in Cognitive Science and \\ Department of Philosophy, Yale University
}

\section{Correspondence}

Sehrang Joo

2 Hillhouse Avenue, Yale University

New Haven, CT, USA, 06511

Email: sehrang.joo@yale.edu

Funding information

The authors have no specific funding to declare.
People often think of objects teleologically. For instance, we might understand a hammer in terms of its purpose of driving in nails. But how should we understand teleological thinking in the first place? This paper separates mere teleology (simply ascribing a telos) and teleological explanation (thinking something is explained by its telos) by examining cases where an object was designed for one purpose but is now widely used for a different purpose. Across four experiments, we show that teleology judgments and teleological explanation judgments are dissociable, and identify three factors that influenced teleology judgments (and one that did not).

\section{KEYWORDS}

Teleology, Purpose, Function, Explanation

\section{1 | INTRODUCTION}

Suppose you observe a piece of metal attached to a piece of wood. Now suppose you begin thinking of this object in terms of a specific purpose: driving in nails. In a case like this one, you are engaged in teleological thinking.

Recent research suggests that teleological thinking impacts a surprisingly broad array of other judgments. For example, studies indicate that if you think of the piece of metal and the piece of wood in terms of a purpose, you will be more inclined to think that they constitute a single object (Rose \& Schaffer, 2017) and that this object belongs to the category of hammers (Matan \& Carey, 2001). This characteristic pattern has also been observed for judgments about essences (Kelemen \& Carey, 2007; Rose \& Nichols, 2019), causation (Lombrozo, 2010), and persistence, (Rose, 2014; Rose, Schaffer \& Tobia, 2020). If teleological thinking does indeed impact all of these different judgments, a question arises as to how to understand teleological thinking itself.

In addressing this question, we make a key distinction: between mere teleology and teleological explanation. Mere teleology is simply a matter of ascribing a specific purpose to an object. One might express this sort of judgment with 
a sentence like: "This hammer is for driving nails." By contrast, teleological explanation is a matter of thinking that the object's telos actually explains why the object is the way it is. Thus one expresses this sort of judgment with a sentence like, "This hammer has a flat end so that it can drive nails."

To what extent are these concepts-mere teleology versus teleological explanation-related? One obvious hypothesis is that the two concepts are quite tightly intertwined. Indeed, it may be that ascribing a teleological explanation is a necessary part of ascribing mere teleology to that object in the first place. What would it even mean to attribute a telos to an object if one thinks that this telos does not explain why the object is the way it is?

In what follows, we offer evidence for a different hypothesis. On this alternative view, people have certain criteria for attributing mere teleology-criteria which do not require explanation. In other words, it may be that people do not necessarily think that something has a teleological explanation when they think it has a telos. Rather, people can easily make sense of the idea that (a) the object has a particular telos but also (b) that telos does not explain why the object is the way it is.

If this alternative hypothesis is correct, there are two distinct senses in which one might say that people are thinking teleologically. On one hand, one might make the strong claim that people think an object has a teleological explanation-that is, that they think its telos explains why it is the way it is. On the other, one might make the weaker claim that people simply think an object has a telos, in a sense that might not involve any further assumptions about explanation. In each of the many different areas in which teleological thinking has been implicated, we would then face a question about precisely which of these forms of teleological thinking is at work. Is it a matter of teleological explanation or a matter of mere teleology?

\subsection{What is teleological explanation?}

To understand the relation between judgments of teleology and teleological explanation, we first need to understand teleological explanation. Teleological explanations refer to something's purpose in order to explain why it exists, and, most paradigmatically, people think that teleological explanations are true when the objects in question were intentionally designed. Just as the hammer might be said to exist precisely because of its purpose in driving in nails, other artifacts (i.e., objects created by humans) typically have teleological explanations because the original creator intended for them to have specific purposes.

These originally intended purposes seem to broadly underlie the acceptance of teleological explanations. For instance, teleological explanations like "Sally's caves are large because larger caves produce audible echoes" tend to perform better when the objects were created for these purpose (e.g., when Sally specifically notices that larger caves produce audible echoes and modifies the caves accordingly) than when their purposes were relevant but not obviously intended (e.g., when Sally notices that everyone prefers the larger caves but not why, Lombrozo \& Carey, 2006). In other words, teleological explanations may be most acceptable when the objects in question were designed for a particular purpose.

However, people sometimes also accept teleological explanations for objects that may not have been explicitly created for a purpose. Most adults, for instance, tend to accept teleological explanations about parts of animals (Kelemen, 1999). One interpretation of this phenomenon is that people think that the parts of animals were actually created for particular purpose (namely, that they were designed for this purpose by God, e.g., Kelemen, 2004; Kelemen, Rottman \& Seston, 2013; Kelemen \& Rosset, 2009), while another interpretation is that the teleological explanations people give in this case are not best understood in terms of a creator's intentions but are instead best understood in some 
other way (e.g., in terms of natural selection; Liquin \& Lombrozo, 2018; Lombrozo \& Carey, 2006; see also Lennox, 1993). In general, teleological explanations are related to objects' causal histories (either through explicit design or through processes such as natural selection).

But to what extent does reasoning about teleological explanation underlie teleological thinking more generally?

\section{2 | Teleology as teleological explanation}

Much of the existing research on teleology judgments might support the view that ascribing a telos to something simply is assigning it a teleological explanation. In other words, people may think of an object as being for some telos only if they think of the object as somehow explained by that telos. Something's causal history or the purpose it was created for may also largely drive when we think something has a telos-and therefore teleological thinking may be largely a matter of explanation.

Indeed, creator's intentions often emerge as a key factor in judgments of object teleology. When asked what an artifact is for, people (including children as young as 4 years old) are likely to agree that it is for the purpose it was designed for-often even when the artifact is being used for a different purpose by someone else (German \& Johnson, 2002; see also Kelemen \& Carey, 2007). People also classify objects into categories with familiar functions based on the purposes that they were created for, judging something which was created for making tea (but used to water flowers) to be a "teapot" (Hall, 1995; Matan \& Carey, 2001), even if the object resembles something used for a different purpose (Rips, 1989). These findings underlie the design stance hypothesis (for discussion, see Kelemen \& Carey, 2007; German \& Johnson, 2002), or the hypothesis that creator's intentions are fully responsible for determining an object's telos.

Thus, if people attribute a telos based on the purpose that an object was created for, then even simply attributing a telos to an object would seem to involve teleological explanation, since both judgments would largely be determined by information about the object's causal history. In this case, it would seem that when teleological thinking impacts different judgments and processes, teleological explanation is itself implicated.

\section{3 | Teleology separate from teleological explanation}

Another hypothesis, however, is that people distinguish between teleology and teleological explanation. In particular, teleology judgments might sometimes not reflect beliefs about creator's intentions, even when teleological explanation judgments do.

Consider the following scenario: Suppose an outdated dictionary in the department's conference room is now used to hold open the door. Nobody ever uses the dictionary as it was originally intended (to look up definitions of words), and in fact everyone thinks that it should be used exclusively for holding open the door. Given that everyone in the relevant community currently sees the object as a doorstop and uses it as a doorstop, might an observer judge that its telos has changed from looking up words to holding open doors? If so, then people may ascribe a telos to this dictionary-turned-doorstop (holding open doors), but this telos may not be explanatory (i.e., its existence is still explained by people looking up definitions of words). While people's current interactions do not change the object's causal history and therefore ought not to affect judgments of teleological explanation, we can imagine that it may nonetheless affect judgments of teleology. In this way, teleology may come apart from teleological explanation-in 
other words, we might say that the current purpose of the object is something other than the purpose that explains its existence.

While much of the research on teleology judgments suggests close ties to teleological explanation, some evidence suggests the contrary: that the sorts of factors illustrated in the dictionary-turned-doorstop example may be relevant to teleology but not to teleological explanation. For instance, when an artifact was bad at its original purpose and someone now uses it for something else, people are more likely to agree that the item is for its new purpose (Rose \& Schaffer, 2017). Further, in at least one case, both adults and children do determine that objects are for something other than their intended purpose, even when the object in question could ostensibly perform both functions well (Siegel \& Callanan, 2007). When told that a kind of novel object was made to trap bugs, but that many people (instead of just one person) now use them to collect raindrops, both adults and children as young as five tended to say that the objects were for collecting raindrops (Siegel \& Callanan, 2007). In this case, people were led to think that the objects were for a purpose that clearly could not explain anything about them (i.e., since this purpose was imposed after the object was created with a different intended purpose in mind). Cases like these demonstrate that teleology judgments may, in some situations, result from something other than a creator's intent. Given that an explanation of these same objects should nonetheless depend on their causal history (and therefore continue to be determined by their design), these cases also suggest that the endorsement of teleology may indicate something different from the endorsement of teleological explanation.

There are also other views on teleology that intrinsically separate teleology from teleological explanation. The relationaldeictic view of teleology (ojalehto, Waxman \& Douglas, 2013), for instance, argues that entities such as trees or animals can be thought of as for something without any presumed history of a creator's intentions. Consider a sentence like: "Trees are for providing oxygen." This is a coherent statement without appeal to explanation. We understand this sentence not as explaining how trees were designed or created, but as an indication of how different entities might interact with it.

In contrast to the view that attributing a telos is closely tied to teleological explanation, the view that these judgments are separable would raise new questions. In particular, if mere teleology and teleological explanations are distinct judgments, then whenever teleological thinking has an impact, we face a question as to whether this impact is driven by judgments of mere teleology or by judgments of teleological explanation.

\section{4 | The present studies}

The present studies were designed with the following general questions in mind: (1) Do mere teleology judgments (e.g., thinking that something has a purpose) always equate to teleological explanation judgments (e.g., thinking that something is explained by its purpose)?; (2) If people think about mere teleology differently from teleological explanation, what factors are involved in ascribing tele to objects?; and (3) How can we tell what kind of teleological thinking-mere teleology versus teleological explanation-is implicated in a given instance?

We begin, in Experiment 1, by contrasting between something's purpose (i.e., teleology) and what may explain it (i.e., teleological explanation). We ask participants to evaluate either the artifact's intentionally designed purpose or a newly assigned purpose, in the context of evaluating either an explanation of the artifact's features or a statement of its purpose. In Experiments 2 to 4, we explore several factors relevant to attributing a telos, which may offer ways to identify mere teleology versus teleological explanation. 


\section{2 | EXPERIMENT 1: TELEOLOGY AND EXPLANATION}

In this experiment, we examine whether judgements of mere teleology come apart from judgments of teleological explanation. Participants were told that all members of a community (e.g., a town) had changed the current practice surrounding an artifact, now considering it to be something different than what it was designed to be. We chose four artifacts that could easily have been made for either of two possible purposes. In one condition, participants were asked to evaluate what "explains" the artifacts' features, or "why the [artifacts] look and feel the way that they do." In another, they were asked to evaluate what the artifacts were "for," or "the purpose of the [artifacts]."

\section{1 | Method}

\subsection{1 | Participants}

Eight hundred adult participants completed a survey online through Amazon Mechanical Turk $\left(\mathrm{M}_{a g e}=36.8, \mathrm{SD}_{a g e}\right.$ $=10.6,75.8 \%$ white, $44.9 \%$ female). All methods and analyses of this experiment were preregistered (preregistrations for this and all following experiments can be found on our OSF page: https : //osf.io/sybgj/?view_on/y = $d a 7 c 2 e 4191804 b f 38 d d 4 c f e 2 a 0413796)$. Data from an additional 21 participants were collected but excluded for failing a comprehension check (see Section 2.1.3).

\subsection{2 | Stimuli}

Each item consisted of a vignette about an artifact that had been designed for one purpose but was now being used for a different purpose. Total materials consisted of four unique artifacts (straws/windchimes, blankets/towels, ice cube trays/organizers, and washboards/percussion instruments). The order of the purposes was counterbalanced (i.e., for half of the subjects, one of the artifacts was designed as a straw but used as a windchime, and vice versa). An example vignette is reproduced below: 
These metal tubes were made as straws. That means that they were designed to move liquids from a cup to someone's mouth.

But one day everyone in the town came together and agreed that the tubes shouldn't be used in drinking liquids and that they should all instead be windchimes. They decided that all of the metal tubes would be used only to make music when the wind blows.

One of two questions was presented along with each vignette. In the explanation condition, participants were asked what explained the artifact's features:

Someone in the town is now wondering about what explains the metal tubes' features. They want to know why the metal tubes look and feel the way that they do.

To what extent do you agree or disagree with the statement: The metal tubes are the way that they are so that they can make music when the wind blows.

In the teleology condition, participants were asked what the artifact was for:

Someone in the town is now wondering about what the metal tubes are for. They want to know the purpose of the metal tubes.

To what extent do you agree or disagree with the statement: The metal tubes are for making music when the wind blows.

Participants were asked about the same purpose (e.g., for the metal tubes, the purpose of being a windchime) regardless of the order of purposes in the vignette. As a result, in the original purpose condition, participants were asked about the artifact's original purpose, and in the new purpose condition, they were asked about the artifact's new purpose. This sample vignette is also shown in Table 1, and the full set is available on our OSF page.

\subsection{3 | Procedure}

In a 2 (purpose: original/new purpose) $\times 2$ (question: explanation/teleology) $\times 4$ (artifact) between-subjects design, participants were randomly assigned to one vignette paired with one kind of question. Regardless of question condition, participants were always asked to rate the extent to which they agreed or disagreed on a scale from 0 to 7 , where 0 was completely disagree and 7 was completely agree. (Note that this scale is not a typical 7-point Likert scale, and the midpoint of the scale is therefore 3.5, as opposed to 4.) Participants were then asked a true or false question about the artifact's original design (e.g., "True or False: The metal tubes were originally designed as straws"); participants who failed this comprehension check were excluded and replaced (see Section 2.1.1). At the end of the survey, participants were asked a series of demographic questions.

\subsection{Results and Discussion}

Results are displayed in Figure 1. Data were analyzed using R with the Ime4 package. Data were fit to linear mixedeffects models, with purpose and question as fixed effects. Artifact was included as a random effect (random intercepts 
TAB LE 1 One complete vignette, with variations from Experiments 1-3. The first row shows the basic set up of each vignette. Slight variations of the second paragraph were included in each experiment. In each successive row, the experiment is labeled with its manipulation, and variations between conditions are marked in bold. Each experiment was also counterbalanced for the order of purposes (e.g., straws or wind chimes) and (in Experiments 2 and 3) for the order of information from each manipulation (e.g., whether present use or collective recognition was shown first). Four total artifacts were used; all vignettes are available on our OSF page.

\begin{tabular}{ll} 
Experiment & Text \\
\hline Introduction (Shown in all experiments) & These metal tubes were made as straws. That means \\
they were designed to move liquids form a cup to \\
someone's mouth.
\end{tabular}

It just so happened, though, that the metal tubes also had the capacity to work like wind chimes and make music when the wind blows. agreed that the tubes shouldn't be used in drinking liquids and that they should all instead be wind chimes. They decided that all of the metal tubes would be used only to make music when the wind blows.

Experiment 2: Present Use \& Collective Recognition Actually, everybody (nobody) in the town used the metal tubes as wind chimes. If you saw a metal tube like this around town, chances are it was (was not) being used as a wind chime.

In fact, everybody (nobody) in the town agreed that the tubes should be used as wind chimes. And if you asked someone at random what the metal tubes were, virtually everybody (nobody) would say that they were wind chimes.

Experiment 3: Current Practice $\&$ Success at a Function

In fact, everybody (nobody) in the town agreed that the tubes should be used as wind chimes, and everybody (nobody) actually used the metal tubes as wind chimes. If you asked someone at random, virtually everybody (nobody) in the town would say that the tubes were wind chimes.

As it turns out, the metal tubes were great (terrible) at being wind chimes. Because of their shapes and sizes, they were really (weren't very) good at making music when the wind blew. They made particularly clear and beautiful sounds (only very quiet and unharmonious sounds). 


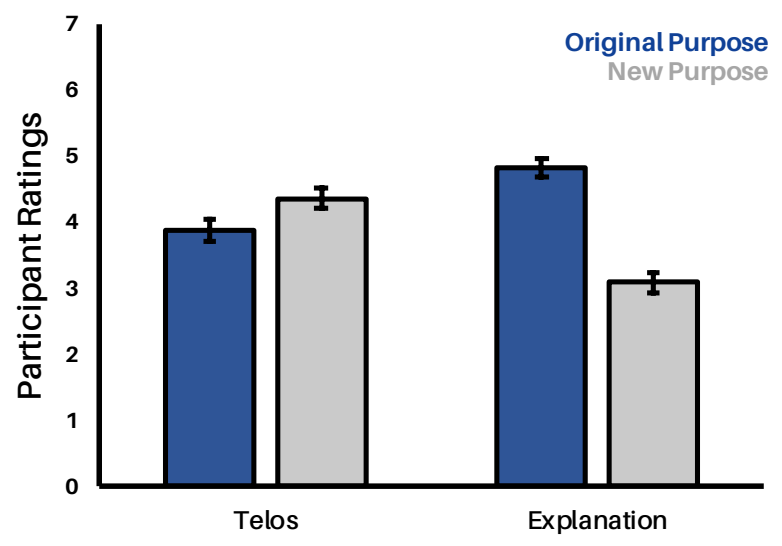

FIGURE 1 Results from Experiment 1 demonstrating that participants differentiate something's telos from its explanation. Responses are collapsed across all four artifacts. Error bars represent + /- $1 \mathrm{SE}$.

only) in all models. There was a significant main effect of Purpose, such that ratings were generally higher for the original purpose $(M=4.35, S D=2.15)$ than the new purpose $(M=3.73, S D=2.22), X^{2}(1)=16.01, p<.001$. There was no significant main effect of question, $X^{2}(1)=1.10, p=.30$. However, there was a significant interaction between question and purpose, $X^{2}(1)=52.90, p<.001$.

To further explore this interaction, we conducted an additional analysis (which was not preregistered) in which we looked separately at each question. When asked about whether the purpose was an explanation of the artifact's features, participants rated the original purpose $(M=4.82, S D=1.94)$ higher than the new purpose $(M=3.09, S D=$ 2.15), $X^{2}(1)=66.02, p<.001$. However, the exact opposite was true when asked about the artifact's telos: Participants now rated the new purpose $(M=4.36, S D=2.17)$ higher than the original purpose $(M=3.88, S D=2.25), X^{2}(1)=4.93$, $p=.026$.

Participants' responses demonstrated that people's attributions of a telos to an object can come apart from their judgments as to whether the object was explained by that telos. If mere teleology judgments were interchangeable with teleological explanation judgments, then both should have exhibited similar patterns. Instead, our participants clearly understood that only an artifact's designed purpose could be an explanation of its features-but showed no such preference in evaluating teleology. In fact, they were actually somewhat more likely to consider the artifact's new purpose as its telos, even though these new purposes were in direct contrast to the purposes they were originally created for. While people's judgments of teleological explanations tracked creator's intentions, these results indicate that their judgments of teleology might instead be driven by a plurality of factors.

\section{3 | EXPERIMENT 2: COLLECTIVE RECOGNITION AND PRESENT USE}

Experiment 1 demonstrated a dissociation between two kinds of teleological thinking-mere teleology versus teleological explanation-that are influenced by different factors. Here, we further explore the factors that affect mere teleology judgments, beginning with current practice. 
A community's current practice (i.e., in the previous experiment when "everyone came together and agreed" that the artifact's purpose was changed) could imply both collective recognition (i.e., that all of the members of the community agree that the artifact should be used for one purpose and not another) and/or present use (i.e., that they do in practice use the artifact for its new purpose). At least in principle, collective recognition and present use may be independent: Suppose that the community together agrees that existing windchimes should be converted into metal straws, but that in practice everybody on their own continues to use their straws as windchimes (resulting in changed recognition but not use). Conversely, without any such collective agreement, everybody on their own might use the windchimes as straws without ever agreeing that they should be used this way (resulting in changed use but not recognition).

Prior research suggests these factors may indeed have separable impacts. However, most prior work on teleology judgments and current practice deals exclusively with present use (e.g., German \& Johnson, 2002; Siegel \& Callanan, 2007). Here, we take "present use" to mean a seemingly permanent change in use by an entire community, rather than a single instance of a new use (as research suggests that single uses do not meaningfully affect telos judgements, e.g., German \& Johnson, 2002; Malt \& Sloman, 2007).

The possible impact of collective recognition is less clear. At least two distinct possibilities are suggested by the existing research. Some existing research suggests that collective recognition only minimally influences teleology judgments (Chaigneau \& Puebla, 2013), while other work argues that collective recognition is key to teleology judgments (Scheele, 2006). Therefore, we have no specific prediction about how collective recognition will affect teleology judgments. Here, we split current use and collective recognition apart as separate factors. Participants were now told that the same four artifacts were either used/not used for the new purposes (e.g., "Everybody/nobody in the town used the [artifacts] as $x^{\prime \prime}$ ) and that they were either recognized/not recognized for their new purposes (e.g., "Everybody/nobody in the town agreed that the [artifacts] should be used as $\left.x^{\prime \prime}\right)$. They were then asked to evaluate the extent to which the artifacts were for their new purpose.

\section{1 | Method}

All elements of the experimental design were identical to those of Experiment 1, except as stated below. Seven hundred and sixty-eight new participants completed a survey online through Amazon Mechanical Turk ( $\mathrm{M}_{\text {age }}=38.2$, $\mathrm{SD}_{\text {age }}=11.9,81.4 \%$ white, $49.9 \%$ female). The sample size was chosen to be similar to that of Experiment 1, while allowing for equal numbers of participants in each of 64 total conditions. Data from an additional 34 participants were excluded. This experiment was also preregistered (available on our OSF page: https: //osf.io/sybgj/?view_only = da7c2e4191804bf 38dd4cf e2a0413796).

The same four artifacts (each with the same two purposes) were used as in Experiment 1. The artifacts were either used/not used for the new purpose (e.g., "Everybody/nobody in the town used the metal tubes as windchimes") and recognized/not recognized (e.g., "Everybody/nobody in the town agreed that the tubes should be used as windchimes") for their new purpose. The order of the purposes (e.g., straws vs. windchimes) and the order of information (e.g., use vs. recognition) were also counterbalanced, resulting in a 2 (use: used/not used) $\times 2$ (recognition: recognized/not recognized) $\times 4$ (artifact) $\times 2$ (order of purposes) $\times 2$ (order of information) design. A sample vignette is shown in Table 1 , and the full set is available on our OSF page.

Along with each vignette, participants were always asked to rate the extent to which they agreed with a statement that the artifact was for its new purpose. This question was phrased identically to the Teleology condition in Experiment 1 (e.g., "Someone in the town is now wondering about what the metal tubes are for. They want to know the purpose of 


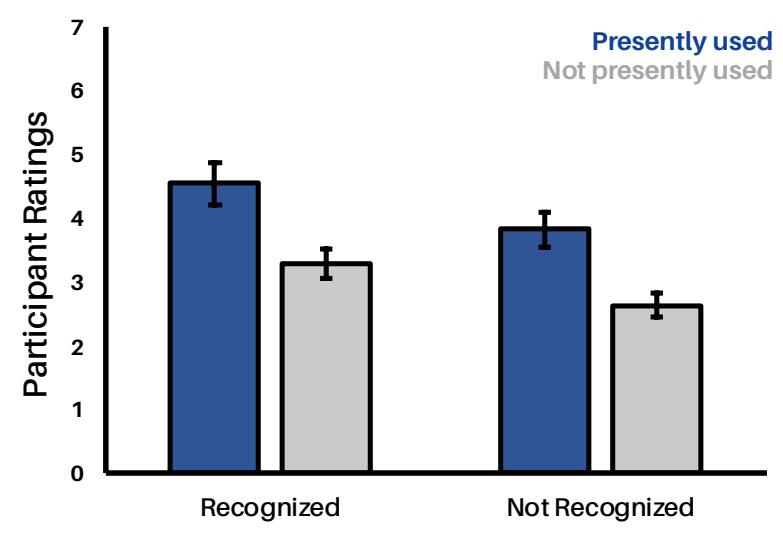

FIGURE 2 Results from Experiment 2 demonstrating the effects of Present Use and Current Recognition. Responses are collapsed across all four artifacts. Error bars represent +/- $1 \mathrm{SE}$.

the metal tubes. To what extent do you agree or disagree with the statement: The metal tubes are for making music when the wind blows.").

\section{2 | Results and Discussion}

Results are displayed in Figure 2. Data were fit to linear mixed-effects models, with use, recognition, order of purposes, and order of information as fixed effects. Artifact was included as a random effect (random intercepts only) in all models. There was a significant main effect of use, such that artifacts that were currently being used for some new purpose ( $M$ $=4.18, S D=2.06)$ generally had higher telos ratings than those that were $\operatorname{not}(M=2.96, S D=2.36), X^{2}(1)=58.74, p<$. 001). Similarly, there was a significant main effect of recognition, such that artifacts that were collectively recognized as being for some new purpose $(M=3.91, S D=2.21)$ generally had higher telos ratings than those that were not $(M$ $=3.22, S D=2.33), X^{2}(1)=19.03, p<.001$. However, there was no significant interaction, $X^{2}(1)=.05, p=.82$. There were no significant main effects of order of purposes, $X^{2}(1)=3.34, p=.07$, or of order of information, $X^{2}(1)=2.98, p=$ .08 .

These results demonstrate the effect of two sources of current practice. Both present use and collective recognition independently affected how people understood what objects are for. In conjunction with Experiment 1, these results suggest that both kinds of information, together, may serve as a significant contrast to a creator's intentions. While we might default to thinking of something's purpose as what it was designed to do, changes in current practice may shift this understanding. When a community both recognizes an object as serving some new function and actively uses it for that new function, such current information may override the creator's intentions in informing what these objects are now for. As a result, at least in some cases, people's judgments of something's telos may change, such that it is decided by something other than their original design.

Though prior research indicates that a single person intending to use an object differently does not significantly weigh against the designer's intentions, an entire community's new intentions does appear to affect teleology judgments. We propose that just as the original designer may indicate some intended purpose for an artifact the community, through collective recognition, may indicate a new purpose for it (Scheele, 2006; Siegel \& Callanan, 2007). 


\section{4 | EXPERIMENT 3: SUCCESS AT A FUNCTION}

Another factor that influences teleological thinking is an object's ability to succeed at a function (Chaigneau et al., 2007; Liquin \& Lombrozo, 2018; Rose \& Schaffer, 2017). For instance, people seem more receptive to an object's new purpose if it was bad at its original purpose: An umbrella-turned-lampshade is more likely thought of as a lampshade if it was a poor umbrella to begin with (Rose \& Schaffer, 2017). Similarly, it might be that people thought of the metal tubes as straws not only because the townspeople agree on this new purpose, but also because the tubes are highly successful straws (whereas they might have been poor or unmelodic windchimes). In this case, the results in our previous experiments could be driven not by collective recognition or present use per se-but by an assumption that either or both of these factors implies that the object is simply better at its new purpose.

Here we examine the role of success at a function alongside the role of a community's current practice; we ask whether an object's ability to succeed at a given function remains a relevant concern even when a community has already agreed it is for that purpose. Since Experiment 2 demonstrated that both current use and collective recognition are involved in teleology judgments, here we again combine these factors into one manipulation. Participants were now told that the same four artifacts were either good at/bad at a new purpose and either currently in practice/not in practice for this new purpose. They were again asked to evaluate the extent to which the artifacts were for their new purpose.

\section{1 | Method}

All elements of the experimental design were identical to those of Experiment 2, except as stated below. Seven hundred and sixty-eight new participants completed the survey online through Amazon Mechanical Turk ( $\mathrm{M}_{\text {age }}=$ 38.2, $\mathrm{SD}_{\text {age }}=11.7,74.9 \%$ white, $46.9 \%$ female). This sample size was chosen to be identical to that in the previous experiment. Data from an additional 34 participants were excluded. This experiment was also preregistered (available on our OSF page: https: //osf.io/sybgj/?view_only =da7c2e4191804bf38dd4cfe2a0413796).

Here, current practice, broken down as used/not used, refers to the combination of present use and collective recognition from Experiment 2. The artifact was now also either good or bad at performing its new purpose (e.g., "Because of their shapes and sizes, they were really good at/weren't very good at making music when the wind blew"), resulting in a 2 (current practice: used/not used) $\times 2$ (success: good at/bad at) $\times 4$ (artifact) $\times 2$ (order of purposes) $\times 2$ (order of information design). A sample vignette is shown in Table 1, and the full set is available on our OSF page.

\section{2 | Results and Discussion}

Results are displayed in Figure 3. Data were fit to linear mixed-effects models, with current practice, success, order of purposes, and order of information as fixed effects. Artifact was included as a random effect (random intercepts only) in all models. There were significant main effects of both current practice and success. Artifacts that were currently being used for some new purpose $(M=3.45, S D=2.94)$ generally had higher telos ratings than those that were not $(M=2.95, S D=2.45), X^{2}(1)=9.74, p=.002$. Similarly, artifacts that were good at accomplishing their new purpose $(M=3.91, S D=2.31)$ generally had higher ratings than those that were not $(M=2.49, S D=2.38), X^{2}(1)=70.11, p<$ .001. There was also a significant interaction, $X^{2}(1)=3.88, p=.049$. 


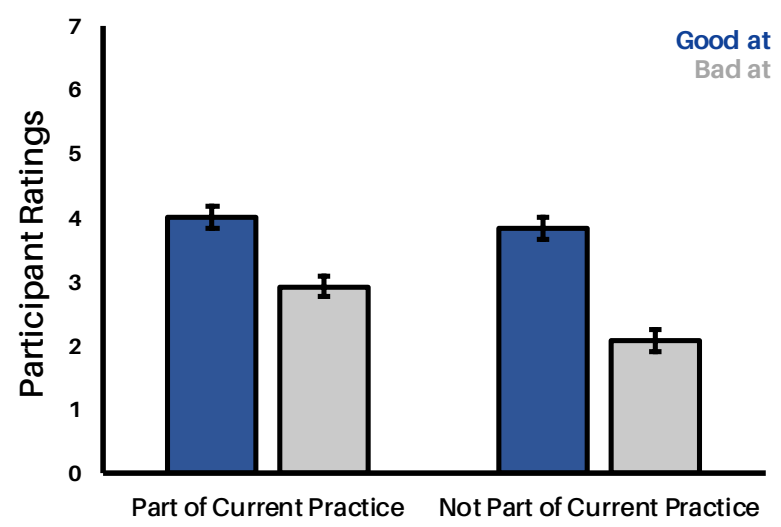

FIGURE 3 Results from Experiment 3 demonstrating the effects of Current Practice and Success at a Function. Responses are collapsed across all four artifacts. Error bars represent +/- $1 \mathrm{SE}$.

To further understand this interaction, we conducted an additional analysis (not preregistered) in which we looked separately at success at a function (good at/bad at) within each current practice (used/not used) condition. Regardless of whether or not the artifact was being used for its new purpose, there was a significant effect of success at a function. However, there was a larger effect of success at a function when the artifact was not being used and thought of in a new way (good: $M=3.82, S D=2.23$; bad: $M=2.07, S D=2.45, X^{2}(1)=53.278, p<.001$ ) than when it was (good: $M=4.00, S D=2.39$; bad: $\left.M=2.92, S D=2.30), X^{2}(1)=20.55, p<.001\right)$. In other words, if a community had already decided that an artifact was for a new purpose, then whether or not the artifact was actually good at that purpose became less relevant. There were no significant main effects of order of purposes, $X^{2}(1)=3.76, p=.053$, or of order of information, $X^{2}(1)=2.48, p=.12$.

These results demonstrate that both success at a function and current practice are factors in determining teleology judgments. They corroborate the idea that success at a given function is an important component in thinking of that function as an object's purpose (e.g., Chaigneau, Barsalou \& Sloman, 2004; Rose \& Schaffer, 2017). These results also demonstrate that the effect of current practice (e.g., present use and collective recognition) cannot be explained by an assumption that the community is changing its practice because the artifact is better at its new purpose. Both success at a function and current practice had independent effects (and in fact, success at a function mattered less in teleology judgments when the community had adopted the new purpose). Rather than being determined by creator's intentions alone, teleology judgments therefore seem to be influenced by at least three other factors: success at a function, present use, and collective recognition.

\section{5 | EXPERIMENT 4: SUCCESS AND STRUCTURE-FUNCTION FIT}

Participants in the prior experiment may have interpreted our manipulation in one of two ways. On the one hand, our participants may have been correctly responding to the artifact's successful output. In this case, whether or not the object is good at performing the function would matter, but further details about how it actually works (e.g., what is going on inside the object itself) would not. For example, we might think of a dictionary-turned-doorstop as for 
stopping doors simply because this function is something it does well, and not because of some further details about its particular features.

On the other hand, success at a function may instead have been interpreted instead as a cue to structure-function fit (see Liquin \& Lombrozo, 2018), in which case our participants may have been responding to changes in structure-function fit rather than in functional success. Observing that an object is good for some function may be akin to observing that its features seem highly fit for the job, in which case a successful output would simply be a cue to understanding the objects' specific features. Something like the metal tubes might be good at being windchimes not only because they successfully create music in the wind, but also because their physical makeup (e.g., that they are hollow, made of metal, and of appropriate sizes to make musical sounds) seem to reflect this purpose. In most typical cases, outward success at a function and structure-function fit is highly correlated, and the fit is what leads to successful output. However, these factors can also be teased apart. Recall the dictionary that was reappropriated as a doorstop: This object is successful at keeping the door open, but the majority of its features (e.g., its pages full of alphabetized words) seem to have nothing to do with the function of stopping doors. In this case, there is low structure-function fit despite the fact that the object is perfectly good at stopping doors.

Structure-function fit has been most implicated in research on judgments of teleological explanation-serving as a cue to understand what makes a good teleological explanation. For example, in cases where people find teleological explanations satisfying, the physical makeup of some particular feature is often clearly connected to the function given in the explanation: For example, something sharp seems well-fitted to cutting, and therefore adults are likely to endorse a teleological explanation like "The knife is sharp so that it can cut things" (Liquin \& Lombrozo, 2018). However, other work has shown that structure-function fit may not always be related to teleological thinking (Korman $\&$ Khemlani, 2020). Examining the influence of this factor on when people attribute a telos may also shed further light on the relationship between their judgments of teleological explanation versus mere teleology.

Experiment 1 showed that teleological thinking can be divided into teleological explanation and mere teleology, and Experiment 3 seemed to demonstrate that success at a given function is an important factor in determining teleology. But is this impact driven by success per se? Or might structure-function fit plays the defining role not only in judgments of teleological explanation, but also in judgments of mere teleology? Here we presented participants with four novel artifacts-designed to be sufficiently complex for manipulations of both whether they were good or bad at this new function and whether their features were or were not particularly well-matched to a given function. In all cases, we sought to control for creator's intentions by noting that "five chemicals were (accidentally) mixed in" during the artifacts' creation. Participants were again asked to evaluate the extent to which the artifacts were for their new purpose.

\section{1 | Method}

All elements of the experimental design were identical to that of Experiment 2, except as stated below.

\subsection{1 | Participants}

Eight hundred new participants completed a survey online through Amazon Mechanical Turk $\left(\mathrm{M}_{a g e}=37.0, \mathrm{SD}_{a g e}=\right.$ 11.2, 76.9\% white, $45.7 \%$ female). This sample size was chosen to be identical to that of Experiment 1, and this experi- 
ment was also preregistered (available on our OSF page: https : //osf.io/sybgj/?view_on/y =da7c2e4191804bf 38dd4cfe2a041 Data from an additional 49 participants were excluded.

\subsection{2 | Stimuli}

This experiment introduced four new artifacts, chosen for a level of internal complexity that allowed for manipulation of structure-function fit. Participants were told that five chemicals that were/were not normally necessary to produce some typical properties for the artifact at hand. For instance, in the Fit condition:

These items were designed as artists' charcoal crayons. While they were being manufactured, five chemicals that aren't usually needed to make good crayons were accidentally mixed in. Regardless, they turned out to work like ordinary artists' crayons.

They were then told that people needed objects that could do some new, unfamiliar purpose (always a nonsense word, e.g., "pyrronifying"). In cases where the five chemicals were not usually related to the artifact's original purpose (e.g., being charcoal crayons), participants were told that the chemicals were involved in this new purpose:

Some people setting off a fireworks display needed to pyrronify their materials. In pyrronification, something is needed to turn bright yellow when burned. The five chemicals that accidentally got mixed into the crayons just so happened to be the exact five chemicals usually involved in this kind of color change.

Finally, participants were told that the artifacts in question were/were not successful at this purpose:

The people setting off the fireworks display noticed that the charcoal crayons seemed like they could do the job, and so they decided to use them in their display. In fact, the crayons turned out to be really great at pyrronifying. They turned bright yellow when burned, exactly as needed.

For narrative clarity, participants were always told the relevant information in this order. Total materials consisted of four such vignettes (mirror, charcoal crayons, photo paper, nail polish). Participants were randomly assigned to 1 of 16 conditions in a 2 (success: good at/bad at) $\times 2$ (structure-function fit: fit/not fit) $\times 4$ (artifact) between-subjects design. This sample vignette, with all conditions, is shown in Table 2.

\section{2 | Results and Discussion}

Results are displayed in Figure 4. Data were fit to linear mixed-effects models, with success and structure-function fit as fixed effects. Artifact was included as a random effect (random intercepts only) in all models. There was a significant main effect of success, such that artifacts that were successful at some new purpose $(M=3.19, S D=2.16)$ generally had higher telos ratings than those that were not $\left(M=1.47, S D=2.15 ; X^{2}(1)=120.99, p<.001\right)$. However, there was no significant main effect of structure-function fit $\left(X^{2}(1)=2.74, p=.10\right)$ and no significant interaction $\left(X^{2}(1)=3.21\right.$, $p=.07)$.

When explicitly divorced from both creator's intentions and success at a function, structure-function fit did not influence teleology judgments. These results demonstrate that success at a function does itself contribute to telos 
TABLE 2 One complete vignette from Experiment 4. The first row shows the background of the vignette; some text (marked in bold) was varied to fit the information in each condition. The following rows show the manipulation of Structure-Function Fit and Success at a Function. The text from each condition (i.e., fit / not fit and good / bad) are shown as separate paragraphs within these rows, with relevant differences marked in bold. One paragraph from each condition (i.e., each row) was included in each vignette. Four total artifacts were used. A complete set of all vignettes is available on our OSF page.

\begin{tabular}{ll} 
Condition & Text \\
\hline Introduction (Shown in all conditions) & These items were designed as artists' charcoal crayons. While they were \\
& being manufactured, five chemicals that are (aren't) usually needed to \\
& make good crayons were (accidentally) mixed in. (Regardless,) they \\
& turned out to work like ordinary artists' crayons.
\end{tabular}

Some people setting off a fireworks display needed to pyrronify their materials.

Structure-Function Fit

In pyrronification, something is needed to turn bright yellow when burned The five chemicals that accidentally got mixed into the crayons just so happened to be the exact five chemicals usually involved in this kind of color change.

In pyrronification, something is needed to burn as fuel in a fire. The charcoal crayons, like a lot of other things, can usually be lit on fire.

The people setting off the fireworks display noticed that the charcoal crayons seemed like they could do the job, and so they decided to use them in their display. In fact, the crayons turned out to be really great at pyrronifying. They turned bright yellow when burned (light on fire), exactly as needed.

The people setting off the fireworks display noticed that the charcoal crayons seemed like they could do the job, and so they decided to use them in their display. In fact, the crayons turned out to be really terrible at pyrronifying. They completely failed to turn yellow when burned (light on fire). 


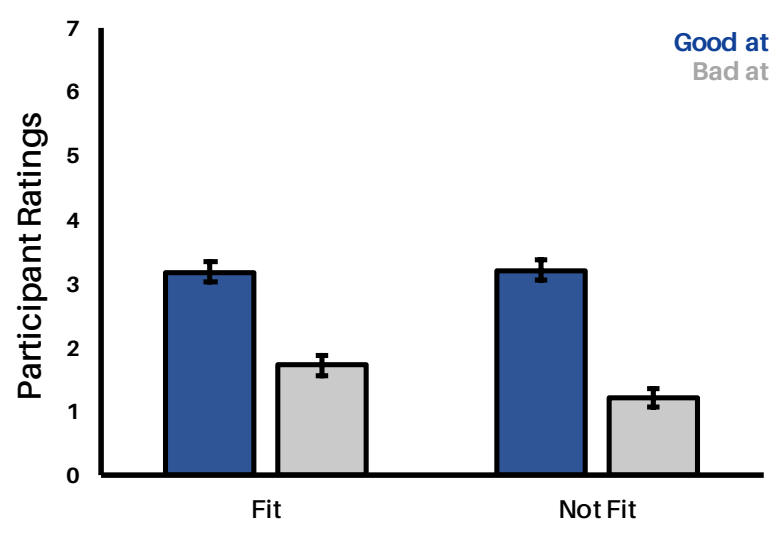

FIGURE 4 Results from Experiment 4 demonstrating the effect of Success, but not Structure-Function Fit. Responses are collapsed across all four artifacts. Error bars represent +/- $1 \mathrm{SE}$.

attributions, and that participants in the previous experiment were likely responding to success rather than implied structure-function fit. Given the respective roles of structure-function fit in each of these concepts, these results also further the distinction between people's thinking about mere teleology and teleological explanation. Structurefunction fit may be relevant in evaluating teleological explanations (Liquin \& Lombrozo, 2018), but consistent with Korman and Khemlani (2020), our findings indicate that it does not impact people's judgments of mere teleology.

\section{6 | GENERAL DISCUSSION}

What does it mean to think about an object teleologically? The experiments reported here demonstrate that teleological thinking can take two forms: mere teleology or teleological explanation. In Experiment 1, people thought that a community could change something's telos without changing its teleological explanation: Teleological explanation judgments were consistently driven by the creator's intent, but mere teleology judgments were also influenced by how people were currently interacting with the artifacts. In Experiment 2, both how a community currently uses an artifact and how they recognize the artifact affected people's teleology judgments. In Experiment 3, success at a function also factored into these judgments. In contrast, Experiment 4 highlighted one factor that does not affect teleology judgments-structure-function fit-despite its established role in teleological explanation (see Liquin \& Lombrozo, 2018).

Attributing a telos to an object does not imply that this telos is explanatory. Instead, teleology seems to result from a combination of factors, not all involved in explanation. Previous research found that the creator's intentions impact teleology judgments (see, e.g., German \& Johnson, 2002; Matan \& Carey, 2001); the present studies found an impact of three additional factors: present use (see also German \& Johnson, 2002; Siegel \& Callanan, 2007), collective recognition (see also Scheele, 2006), and success at a function (see also Chaigneau et al., 2007; Rose \& Schaffer, 2017). The impact of these additional factors on teleology judgments-as well as the divergence between these judgments and judgments of teleological explanation-suggest the need to characterize teleology as separate from teleological explanation. 


\subsection{Why these four factors?}

At first glance, creator's intentions, present use, collective recognition, and success at a function seem like four separate and very different factors. The impact of all four of them on teleology judgments immediately raises the question: Why these four things, as opposed to others (such as structure-function fit)?

One way to approach this question is to consider ways in which two or more of these factors may be understood together. For example, both creator's intentions and collective recognition may both be ways that intentions affect teleology judgments. In line with Scheele (2006), these results suggest that the relevant aspect to creator's intentions may be something about intentions and not something specific to the original creator (see also Chaigneau \& Peubla, 2013 for a contrasting perspective). While the original creator's intended use may carry particular weight compared to another single individual's, the current community may also dictate an intended use for an object. In these cases (such as when a community decides that metal tubes that were once straws should be used as windchimes), the new intention may even override the original intention. Objects' purposes may be embedded in both the creator's and the community's intentions. This focus on intentions may thus explain why both the creator's intentions and collective recognition affect teleology judgments.

One way to better understand the role that intentions play in judgments of teleology would be to test domains in which there is no intentionality. For example, animals have organs that have clear functions, although these functions were not designed; they were a byproduct of evolution by natural selection. Sometimes, though, structures that evolved for one function are used for something else. For example, a heron's wings evolved for flying, yet those wings also facilitate fishing. The wings were neither designed for fishing nor were they naturally selected for fishing, and yet we can still ask about whether the wings are for fishing. Cases of "exaptation" like this one (Gould \& Vrba, 1982) can help us to understand how the factors we have identified here influence teleology judgments, even in the absence of intentionality. If we find that cases like this one show a different pattern from the one observed in cases that involve intention, we would have evidence that intention is playing a genuine role in teleology judgments, whereas if we find that they show the very same pattern, we would have evidence that the pattern is not in fact driven by intention.

Another way to understand the joint influence of multiple factors may be to consider norms. Existing research suggests that people's representation of "normal" behavior combines statistical information (frequent behavior) and prescriptive information (ideal behavior, e.g., Bear \& Knobe, 2017; Bear, Bensinger, Jara-Ettinger \& Knobe, 2020; Phillips \& Cushman, 2017; Wysocki, 2020). Something's purpose may be thought of, in part, as its "normal" use-in which case we would expect the same influence of both statistical and prescriptive information. In fact, present use straightforwardly captures an object's typical use, and success at a function captures what might be an ideal use. In this way, an understanding of norms may offer a way to understand why both present use and success at a function affect teleology judgments.

Each of these theories offer a way to jointly understand two out of four factors that affect teleology judgments. But might there also be a way to understand the impact of all four factors in some broader way? Perhaps one common thread across all four factors is an emphasis on relational information, informing what someone encountering an object for the first time ought to do with it. In this case, teleology may generally be in line with the relational-deictic view of teleological thinking in nature (ojalehto et al., 2013). How the designer intended it to be used, how the people around you currently do use it and think it should be used, and what it can actually do well might all be relevant factors to understanding how you interact with or use an object. These possibilities for bringing together what appear to be 
four disparate factors remain highly speculative for now, but raise new questions that may be addressed by future work.

\section{2 | Two concepts of purpose?}

A reviewer raised the possibility that people may not have a single concept of teleology that is affected by all four of these different factors. Instead, it might be that people's use of English expressions like "is for" is affected by all of these different factors because these expressions are themselves ambiguous. On this alternative hypothesis, it might not be the case that there is a single concept of teleology within the mind. Rather, there might actually be two distinct concepts-one closely tied to original intentions, the other closely tied to current practice. In this case, it may simply be that English expressions like "is for" are ambiguous between these two concepts.

Our studies do provide some support for this possibility: The distributions of responses in one condition of Experiment 1 appear to be bimodal (when participants are asked to evaluate a statement about what the object was for; see supplementary materials on our OSF page), possibly indicating that different participants were responding to the prompt in qualitatively different ways.

Future research should explore this possibility in more detail. On one hand, it may turn out that this is not in fact the case, and that there actually is a single, unified concept of teleology-one that is affected both by creator's intentions and by current practice. In defense of this first hypothesis, note that we observed bimodal distributions in multiple experiments comparing not only original intentions and current practice, but also use, collective recognition, and success at a function (again, see supplementary materials on our OSF page). In light of the fact that we find bimodal distribution in all of these cases, there might be reason to suspect that the bimodal distributions are not best explained in terms of an ambiguity in the question. A different explanation for these bimodal distributions of responses would be that participants interpreted our continuous measure in a categorical way. In other words, if we asked the question: "Is this object for making music?" participants could be thinking about this question as one with a dichotomous answer, that is, the object is either for making music, or it is not. If true, this could lead to participants responding in a bimodal way-but not because the question itself was ambiguous.

On the other hand, it might be that there truly are two different concepts of teleology at work here. This second hypothesis opens up an intriguing new interpretation of the present findings. In our studies, the majority of responses attribute to the object the purpose that accords with current practice, but there is always a minority that do not. The obvious interpretation of these results would involve a single underlying concept such that people's use of this concept is affected especially by factors related to current practice, but is also affected by various other factors. By contrast, this second hypothesis suggests that this minority of responses actually reflect the existence of a distinct concept, such that the use of this other concept is not affected primarily by current practice but is instead affected by other factors entirely. Future research should continue to explore this idea.

For example, one possibility is that laypeople distinguish between "purpose" and "true purpose"-and that while we have primarily studied the former, this other concept may be best described by the latter. For example, suppose a person says that there is a "true purpose of philosophy." Such a person might think that this "true purpose" is something radically different from anything found in the current practice of philosophy. Indeed, she might think that the present practice within the discipline of philosophy involves a betrayal of the true purpose of philosophy. Similar judgments of "true purpose" may be possible in many other domains: The true purpose of friendship, the true purpose of art, the true purpose of your own life, or even the true purpose of different animals (see Rose \& Nichols, 2019, 2020). 
A related possibility is that it may be that this other notion of teleology is the one at work in recent studies that provide evidence of "teleological essentialism" (Rose \& Nichols, 2019, 2020). On this view, there might be some important sense in which people sometimes see the essence of a category as constituted by its telos, but without thinking that the essence of a category is ever constituted by its present use. Rather, insofar as some notion of teleology plays a role in psychological essentialism, it may be this other notion of teleology (true purpose), distinct from the one that is primarily a matter of current use.

If this second hypothesis does turn out to be correct, the present studies would still reveal something quite fundamental about the concept this other notion of teleology. They would show, surprisingly, that this concept is not the same concept that people most commonly invoke when engaged in straightforward judgments about the purposes of artifacts.

\section{3 | If not for explaining, what is teleology for?}

On the view that teleology and teleological explanation were closely tied together, attributing a telos to something could be understood in terms of explanation. In other words, here both teleological statements like "The knife is for cutting food" and "The sun is for providing heat and light" might serve to offer explanations for these objects' existences, and the appeal of teleological thinking would therefore center around the appeal of such explanations. However, the present studies suggest that people's judgments of teleology and teleological explanation are not so intertwined. This raises a new question: Why do we attribute a telos to an object if not to attribute an explanation?

Efforts to bring together each of the factors that impact teleology judgments may shed light on this further question of what value these telos attributions may offer. Might teleology, for instance, helpfully communicate relevant people's intentions-or offer normative information about something's use? A relational view of teleology (see ojalehto et al., 2013) may still capture how teleology is alluring, but without needing to explain. Imagine, for example, a child encountering a microwave for the first time. Learning that this machine is for heating up food may help someone both predict how other agents might interact with it and figure out how to interact with it themself. Critically, none of this information is explanatory and yet it seems highly valuable. Future work may investigate this and other alternatives to understanding the allure of mere teleology, separate from teleological explanation.

\subsection{The impact of recharacterizing teleology}

Teleological thinking pervades human cognition-affecting not only how we think about things like category membership (Matan \& Carey, 2001), mereology (Rose \& Schaffer, 2017), and persistence (Rose et al., 2020), but also how we view the world itself (e.g., as "designed" or not). The present results suggest a distinction between two forms of teleological thinking: mere teleology and teleological explanation. A question arises, then, about the extent to which each of these two forms are relevant to each of the myriad of cognitive processes that seem to involve teleological thinking.

The present results identified four different factors that influence judgments of mere teleology. Understanding how these four factors influence different cognitive processes can help us to understand what kind of teleological thinking is implicated in each of these cases. If a judgment is being driven by mere teleology, we should expect it to be affected by all four factors that influence mere teleology judgments (original intention, present use, community recognition, success). Moreover, we should expect the characteristic pattern observed in these present studies: If a given function 
of an object does satisfy the criteria of present use, community recognition, and success, then we may consider this function to be the telos of that object-even if it does not satisfy the criterion of creator's intentions. By contrast, if the judgment is driven by teleological explanation, we should find a very different pattern. As observed in Experiment 1 , these same three factors (without creator's intentions) are insufficient to change or create a teleological explanation.

To take one example, consider the case of judgments about category membership. Existing research suggests that these judgments are influenced in some way by teleological thinking, meaning that, for example, people's judgment as to whether a given object falls into the category of hammers should depend in part on whether they think of that object in terms of the teleology of driving in nails (e.g., Chaigneau et al., 2004; Hall, 1995; Matan \& Carey, 2001). But should these judgments be understood in terms of mere teleology or in terms of teleological explanation? One way to address this question might be to examine cases in which (a) an object is used for hammering in nails, (b) everyone in the community thinks that it should be used for hammering in nails, (c) it is very successful at hammering in nails, but (d) it was not created with the intention of being used for hammering in nails, but rather with some other intention. Whether or not people judged such an object to fall into the category of hammers would provide insight into whether their category membership judgments are driven by mere teleology or by teleological explanation. A similar method could also be applied to each of the other types of judgments that are influenced by teleological thinking (judgments of essence, persistence, mereology, etc.).

The present findings may also shed some light on people's application of teleological thinking to other sorts of objects, including natural kinds (Heywood \& Bering, 2013; see also Kelemen et al., 2013; Kelemen \& Rosset, 2009), life events (Banerjee \& Bloom, 2014), and even human beings (Lewry et al., 2013). Quite strikingly, people sometimes endorse teleological explanations for such objects, even though they lack obvious human designers. For example, if a person is asked "Why does that mountain exist?" she might respond: "The mountain exists so that goats can graze on it." This response seems to be applying a teleological explanation to an object that arose naturally and was thus not made by people. As a result, it is often thought that responses like this one involve a commitment to some sort of mystical or supernatural cause (e.g., Kelemen et al., 2013; Kelemen \& Rosset, 2009; Rose, 2020). The tendency to give such responses has been explored in detail within existing research, which also sheds light on what factors make people more or less likely to accept teleological explanations for naturally occurring objects (Kelemen et al., 2013; Liquin \& Lombrozo, 2018; Lombrozo \& Carey, 2006).

Importantly, the present findings suggest that merely attributing a telos to a naturally occurring object need not involve any sort of teleological explanation in this sense. Consider a person who simply says: "That mountain is for grazing goats." On the view we develop here, the fact that someone makes this judgment does not itself require that she think the mountain has a teleological explanation. Rather, the person might arrive at the judgment purely on the basis of present use, collective recognition, and success. Thus, the claim that the mountain has a telos might not involve anything mystical or supernatural. It might simply reflect certain relatively mundane views about people's practices and how successful different objects are for those practices (see also Joo, Yousif, \& Keil, 2021).

Making this distinction leads to a variety of further empirical questions. Existing research implicates people's teleological thinking about naturally occurring objects, in particular, in numerous further judgments about such objects (including judgment of causation, persistence, and mereology; see Lombrozo, 2010; Rose et al., 2020; Rose \& Schaffer, 2017). For each such judgment, we now face a question as to whether teleological explanation or mere teleology is the relevant influence. If the former, we might potentially conclude that this judgment is being influenced by a view that is mystical or supernatural. But if the latter, we might instead conclude that it is being influenced by a more straightforward judgment about people's practices. 


\subsection{Conclusion}

What does it mean to think about an object in terms of a particular teleology? Here, we distinguish between judgments of mere teleology and teleological explanation. While the two concepts often go hand in hand, merely ascribing a telos to an object does not require teleological explanation. Instead, mere teleology involves multiple factors that center around a community's current practice. Differentiating these concepts raises new questions for each of many areas where teleological thinking is implicated. 


\section{Acknowledgments}

For helpful comments and conversation, we thank Frank Keil, David Rose, Sangeet Khemlani, Joanna Korman, an anonymous reviewer for Mind \& Language, and the members of the Yale Cognition and Development Lab and the Experimental Philosophy Lab. This project was supported by a National Science Foundation Graduate Research Fellowship awarded to S. R. Yousif. The authors have no known conflicts of interest to report. 


\section{References}

Banerjee, K., \& Bloom, P. (2014). Why did this happen to me? Religious believers' and non-believers' teleological reasoning about life events. Cognition, 133, 277-303.

Bear, A., Bensinger, S., Jara-Ettinger, J., \& Knobe, J. (2020). What comes to mind? Cognition, 194, 104057.

Bear, A., \& Knobe, J. (2017). Normality: Part descriptive, part prescriptive. Cognition, 167, 25-37.

Chaigneau, S. E., Barsalou, L. W., \& Sloman, S. A. (2004). Assessing the causal structure of function. Journal of Experimental Psychology: General, 133, 601.

Chaigneau, S.E. \& Puebla, G. (2013). The proper function of artifacts: Intentions, conventions, and causal inferences. Review of Philosophy and Psychology, 4, 391-406.

German, T., \& Johnson, S. A. (2002). Function and the origins of the design stance. Journal of Cognition and Development, 3, 279-300.

Gould, S.J. \& Vrba, E.S. (1982). Exaptation-a missing term in the science of form. Paleobiology, 8, 4-15.

Hall, D. G. (1995). Artifacts and origins. Unpublished manuscript, University of British Columbia.

Heywood, B. T., \& Bering, J. M. (2013). "Meant to be": How religious beliefs and cultural religiosity affect the implicit bias to think teleologically. Religion. Brain, and Behavior, 4, 183-201.

Joo, S., Yousif, S.R., \& Keil, F.C. (2021). Understanding 'Why': How implicit questions shape explanation preferences. PsyArXiv.

Kelemen, D. (1999). Why are rocks pointy? Children's preference for teleological explanations of the natural world. Developmental Psychology, 35, 1440-1452.

Kelemen, D. (2004). Are Children "Intuitive Theists"?. Reasoning About Purpose and Design in Nature. Psychological Science, 15, 295-301.

Kelemen, D., \& Carey, S. (2007). The essence of artifacts: Developing the design stance. In E. Margolis \& S. Laurence (Eds.), Creations of the Mind: Theories of artifacts and their representation (pp. 212-230). New York: Oxford University Press.

Kelemen, D., \& Rosset, E. (2009). The Human Function Compunction: Teleological Explanation in Adults. Cognition, $111,138-143$.

Kelemen, D., Rottman, J., \& Seston, R. (2013). Professional Physical Scientists Display Tenacious Teleological Tendencies: Purpose-Based Reasoning as a Cognitive Default. Journal of Experimental Psychology: General, 142, 1074-1083.

Korman, J. \& Khemlani, S. (2020). Teleological generics. Cognition, 200, 104157.

Lennox, J. G. (1993). Darwin was a teleologist. Biology \& Philosophy, 8, 409-421. 
Lewry, C., Kelemen, D., \& Lombrozo, T. (2020). People view humans as existing for purposes and condemn those who fail to fulfill them. Proceedings of the 41st Annual Conference of the Cognitive Science Society. Toronto, ON: Cognitive Science Society.

Liquin, E. G., \& Lombrozo, T. (2018). Structure-function fit underlies the evaluation of teleological explanations. Cognitive Psychology, 107, 22-43.

Lombrozo, T. (2010). Causal-explanatory pluralism: How intentions, functions, and mechanisms influence causal ascriptions. Cognitive Psychology, 61, 303-332.

Lombrozo, T., \& Carey, S. (2006). Functional explanations and the function of explanation. Cognition, 99, $167-204$.

Malt, B.C., \& Sloman, S.A. (2007). Category essence or essentially pragmatic? Creator's intention in naming and what's really what. Cognition, 1055, 615-648.

Matan, A., \& Carey, S. (2001). Developmental changes within the core of artifact concepts. Cognition, 78, 1-26.

ojalehto, b., Waxman, S.R., and Douglas L.M. (2013). Teleological Reasoning About Nature: A creator's intentions or Relational Perspectives? Trends in Cognitive Sciences, 17, 166-171.

Phillips, J., \& Cushman, F. (2017). Morality constrains the default representation of what is possible. Proceedings of the National Academy of Sciences, 114, 4649-4654.

Rips, L. J. (1989). Similarity, typicality and categorization. In S. Vosniadou \& A. Ortony (Eds.), Similarity and analogical reasoning (pp. 21-59). Cambridge, England: Cambridge University Press.

Rose, D. (2014). Persistence through function preservation. Synthese, 192, 97-146.

Rose, D. (Forthcoming). Mentalizing Objects. In Oxford Studies in Experimental Philosophy 4. Oxford, England: Oxford University Press.

Rose, D. and Nichols, S. (2019), Teleological Essentialism. Cognitive Science, 43: 12725.

Rose, D. and Nichols, S. (2020), Teleological Essentialism: Generalized. Cognitive Science, 44: 12818.

Rose, D., \& Schaffer, J. (2017). Folk Mereology is Teleology. In D. Rose (Ed.), Experimental Metaphysics (135-186). New York: Bloomsburg Academic.

Rose, D., Schaffer, J., \& Tobia, K. (2020). Folk teleology drives persistence judgments. Synthese, 196, 5491-5509.

Scheele, M. (2006). Function and the use of technical artefacts: The social conditions of function assignment. Studies in History and Philosophy of Science, 37, 23-36.

Siegel, D., \& Callanan, M. (2007). Artifacts as conventional objects. Journal of Cognition and Development, 8, $183-203$.

Wysocki, T. (2020). Normality: A two-faced concept. Review of Philosophy and Psychology, 1-28. 